\title{
Avaliação de parâmetros de crescimento na cultura do Tagetes patula em ambiente protegido e a campo ${ }^{(1)}$
}

\author{
MILLENA ARIANA BOUERI(2); RAÚL ANDRES MARTINEZZ(3); \\ DALVA MARTINELLI CURY LUNARDI(4)
}

\begin{abstract}
RESUMO
A análise quantitativa de crescimento tem sido usada por pesquisadores de plantas na tentativa de explicar diferenças no crescimento, de ordem genética ou resultante de modificações no ambiente. O objetivo deste trabalho foi avaliar parâmetros de crescimento da cultura do Tagetes patula (cravo-de-defunto), em todos os seus estádios fenológicos, em ambiente protegido e a campo. O experimento foi conduzido na área experimental do Departamento de Recursos Naturais - Setor Ciências Ambientais da Faculdade de Ciências Agronômicas da Universidade Estadual Paulista, Campus de Botucatu, no período de 21/05 a 09/08/02. O experimento foi constituído de duas áreas de $280 \mathrm{~m}^{2}$, sendo uma na condição de campo e outra em ambiente protegido tipo arco, com cobertura de polietileno de baixa densidade (PEBD), difusor de luz, com $150 \mu \mathrm{m}$ de espessura, tendo nas laterais "sombrite" com $50 \%$ de redução da radiação solar. Os resultados mostraram que dentro do ambiente protegido, os valores da altura média das plantas, número médio de folhas por planta, área foliar e índice de área foliar médio foram maiores que na condição de campo. O comprimento das raízes e o número de botões florais não apresentaram diferenças significativas entre as duas condições de cultivo. As plantas do ambiente protegido apresentaram flores de melhor qualidade, evidenciado a influência positiva do ambiente protegido neste parâmetro.

Palavras-chave: área foliar, botões florais, plasticultura, cravo-de-defunto.
\end{abstract}

\section{ABSTRACT \\ Evaluation of the growth of the parameters in Tagetes patula crop, inside and outside the greenhouse}

\begin{abstract}
The quantitative analysis of the growth has been used by plant researchers trying to explain the differences in the growth, the genetic or the result of changes in the environment. The objective of this work was to evaluate the growth of the parameters in the Tagetes patula crop, inside and outside the greenhouse. The experiment was carried in the experimental area of the Department of Natural Resources - Section Environmental Sciences of the Faculdade de Ciências Agronômicas, UNESP, Botucatu-SP, 21/05/02 to $09 / 08 / 02$. The experimental area was constituted of two areas of $280 \mathrm{~m} 2$, being one in the field condition and the other one in greenhouse "arch type", with polyethylene low density (LDPE) covering, light difusor, with 150m of thickness, and polypropylene screen with $50 \%$ of solar radiation reduction in the lateral. The results showed that inside the greenhouse the values of the average height of the plants, average leaf number for plant, foliar area and average index of foliar area had been greater than in the field condition. The length of the roots and the number of floral buttons had not presented significant differences between the two conditions of culture. The plants of the greenhouse had presented flowers of better quality, evidenced the positive influence of the greenhouse in this parameter.
\end{abstract}

Keywords: foliar area, floral buttons, plasticulture, Marigold.

\section{INTRODUÇÃO}

Conhecido por "Marigold" em países de língua inglesa, o Tagetes é nativo do México, onde é muito importante na decoração do "Dia dos Mortos" (finados), uma festa muito popular, motivo pelo qual é chamado de "cravo-de-defunto", sendo uma planta de fácil cultivo, bastante decorativa e de ciclo relativamente longo (CLARCK e WILLIAMSON, 1979; FLORTEC, 1998).

Pertence à Família Asteraceae, contendo mais de 50 espécies das quais somente seis anuais e três perenes são atualmente cultivadas. Tagetes erecta L., Tagetes patula L., Tagetes signata L. e Tagetes tenuifolia Cav. são as quatro espécies anuais mais cultivadas como ornamentais em todo o mundo. As folhas desta planta são compostas, de coloração verde escura, produzindo contraste acentuado com as flores (CLARCK e WILLIAMSON, 1979).

O Tagetes patula é uma planta herbácea anual de caule baixo, de 20-30 cm de altura, compacta, de folhagem com cheiro característico, flores em capítulos pequenos simples ou dobrados, solitários, apresentando tonalidades variáveis de amarelo, alaranjado e marrom-avermelhado, sendo cultivado quase que exclusivamente em bordaduras e em forração, formando maciços compactos desenhados, e em canteiros de terra enriquecida com húmus; e também como flor-de-corte (LORENZI e SOUZA, 1995).

Segundo LORENZI e SOUZA (1995), o Tagetes patula é uma planta de pleno sol e de grande resistência, sendo uma das poucas espécies anuais que pode ser cultivada em regiões tropicais durante o período do verão. A cultura requer irrigação suplementar, podendo ser utilizada irrigação por sulco ou aspersão (MEDINA e BEMILLER, 1993). As sementes germinam em qualquer época do ano em sementeiras, podendo ser plantadas diretamente nos canteiros, a uma distância de 30 a $40 \mathrm{~cm}$ entre as mudas dos tipos mais altos e de $15 \mathrm{~cm}$ entre as das variedades menores (ENCICLOPÉDIA DE PLANTAS E FLORES, 1977).

Além de ser utilizado como planta ornamental, tem elevada importância econômica e comercial, devido suas características medicinais e farmacêuticas. Foram observados efeitos terapêuticos significantes sobre carcinomas in vitro e em problemas hepáticos (VASILENKO et al., 1990), sendo também rica em flavonóides e carotenóides, pigmentos importantes para a fabricação de corantes naturais.

\footnotetext{
(1) Parte da Tese de Mestrado da primeira autora, apresentada à FCA/UNESP, Botucatu-SP, financiada pela CAPES. Recebido para publicação em 01/10/2007 e aceito em 09/08/2010.

(2) End.: Rua Dom Daniel Baeta Neves, 382 - Bairro: Mangabeiras - Cep: 35700436 - Sete Lagoas, MG. Email: millenaboueri@hotmail.com

(3) Doutorando do Curso de Irrigação e Drenagem - FCA/UNESP - Botucatu-SP. E-mail: raulmartinez@fca.unesp.br

(4) Docente do Depto. de Recursos Naturais - FCA/UNESP - Botucatu-SP - CP: 237, CEP: 18603070. E-mail: lunardi@fca.unesp.br
} 
A produção de metabólitos secundários, principalmente thiophenos, faz com que esta planta apresente uma variedade de efeitos, tais como nematicida, bactericida, fungicida e inseticida (VASUDEVAN et al., 1997). Seu efeito fungicida tem despertado interesse, sendo estudado extensivamente seus componentes químicos inibidores no desenvolvimento de fungos como o Sclerotium cepivorum que ocorre na cultura da cebola, Colletotrichum gloeosporioides na mangueira e Alternaria solani na cultura da batata (TYGADLO et al., 1993).

Para HUANG (1984), a rotação com esta cultura é um método efetivo para controlar nematóides e insetos em ambientes protegidos, sendo uma das plantas mais utilizadas para este fim. Este mesmo autor em experimento com cenoura e cravo-de-defunto em ambiente protegido, observou redução na população de Meloidogyne javanica, mostrando que rotações com a cultura de interesse, não servem somente para controlar nematóides, mas também para melhorar o solo do cerrado brasileiro, especialmente durante a estação chuvosa. ODUOR-OWINO e WAUDO (1994) observaram o mesmo efeito em um estudo com intercalação de tomate e cravo-dedefunto (Tagetes minuta) em ambiente protegido. Segundo KÄMPF (2000), sua permanência no campo por quatro meses e meio é suficiente para eliminar os nematóides do solo.

HACKNEY e DICKERSON (1975) avaliaram em ambiente protegido, o potencial nematicida do Tagetes sp., feijão e crisântemo, cultivados simultaneamente com o tomate, hospedeiro do Meloidogyne incognita e Pratylenchus alleni, concluindo que o mais eficaz foi o Tagetes sp. Segundo BELCHER e HUSSEY (1977), o efeito nematicida é mais eficaz contra o ataque de Meloidogyne incognita em um esquema de rotação de cultura, do que plantado junto com tomate. Segundo os mesmos autores, o efeito do Tagetes patula foi $27 \%$ maior que o amendoim, um não hospedeiro, na redução de Meloidogyne incognita.

BOUERI (2003), em estudo sobre as necessidades hídricas do Tagetes patula, definiu quatro estádios de desenvol- vimento para a planta, de acordo com o seu índice de área foliar: Estádio I: Inicial (1a a 3a semana após o transplantio); Estádio II: Desenvolvimento Vegetativo (4a a 7a semana); Estádio III: Floração (8a a 11a semana); Estádio IV: Senescência (12a semana). Através do estudo das interações dos parâmetros de crescimento com os estádios de desenvolvimento da planta, podem ser conhecidas a eficiência do crescimento e a habilidade de adaptação às condições ambientais em que estas plantas crescem. Portanto, independente das dificuldades inerentes ao nosso conhecimento sobre a complexidade que envolve o crescimento das plantas, a análise quantitativa do crescimento é uma ferramenta e o meio mais acessível e bastante preciso para avaliar o desenvolvimento vegetal e a contribuição de diferentes processos fisiológicos sobre o seu desempenho, nas diferentes condições de cultivo a que são submetidos.

Dada a ausência de dados relativos a esta cultura e por possuir características tão importantes, este trabalho teve como objetivo avaliar parâmetros de crescimento da cultura do Tagetes patula (cravo-de-defunto), em todos os seus estádios fenológicos, em ambiente protegido e a campo.

\section{MATERIAL E MÉTODOS}

\subsection{Descrição geral da área experimental e condução}

O trabalho foi realizado na área experimental do Departamento de Recursos Naturais - Setor Ciências Ambientais da Faculdade de Ciências Agronômicas da Universidade Estadual Paulista, Campus de Botucatu-SP (latitude 22 $51^{\circ}$ 'S; longitude $48^{\circ} 26^{\prime} \mathrm{W}$ e altitude $786 \mathrm{~m}$ ), durante o período de 81 dias (21/05 a 09/08/2002).

O clima de Botucatu, segundo a classificação de Köeppen, é do tipo Cwa, caracterizado como clima temperado quente com chuvas no verão e seca no inverno. O resumo das condições meteorológicas ocorridas durante o período experimental está apresentado nas Figuras 1, 2 e 3 (BOUERI, 2003).

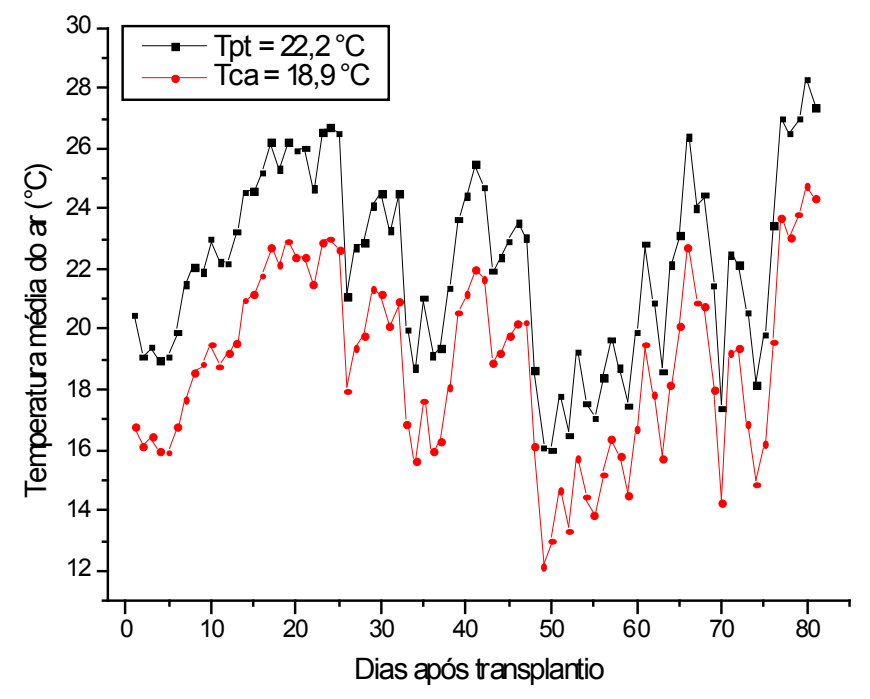

Figura 1. Variação média diária da temperatura do ar, durante o ciclo da cultura do Tagetes patula, em ambiente protegido (pt) e campo (ca).

Figure 1. Average daily variation of the air temperature during the crop cycle of Tagetes patula in greenhouse (pt) and field (ca). 


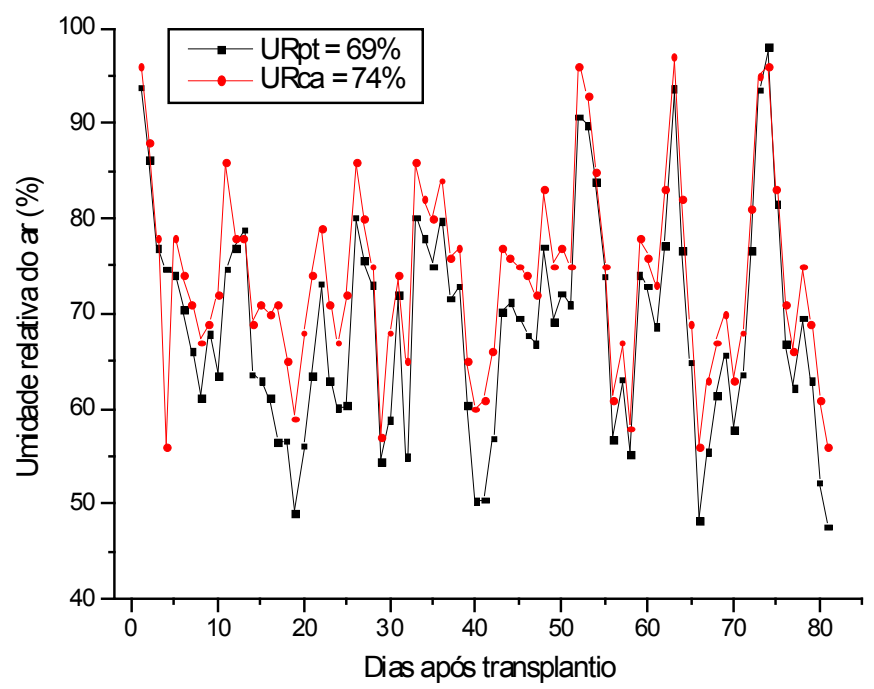

Figura 2. Variação média diária da umidade relativa do ar, durante o ciclo da cultura do Tagetes patula, em ambiente protegido (pt) e campo (ca).

Figure 2. Average daily variation of the relative humidity during the crop cycle of Tagetes patula in greenhouse (pt) and field (ca).

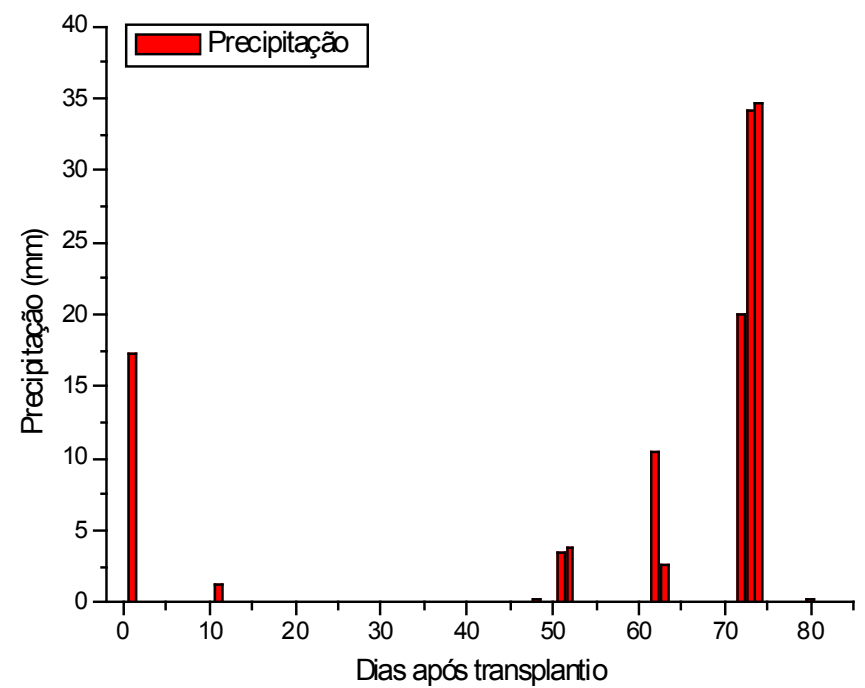

Figura 3. Medida da precipitação pluvial (mm), durante o ciclo da cultura do Tagetes patula, na condição de campo.

Figure 3. Measurement of rainfall $(\mathrm{mm})$ during the crop cycle of Tagetes patula in field condition.

O experimento foi conduzido em duas áreas de $280 \mathrm{~m}^{2}$, orientadas no sentido NNW-SSE, sendo a primeira no campo e a segunda constituída por um ambiente protegido tipo arco, com $7 \mathrm{~m}$ de largura, $40 \mathrm{~m}$ de comprimento, $4 \mathrm{~m}$ de altura máxima e $2,2 \mathrm{~m}$ de pé direito. Utilizou-se a cobertura de polietileno de baixa densidade (PEBD), difusor de luz, com $150 \mu \mathrm{m}$ de espessura, tendo nas laterais "sombrite" (50\% de redução da radiação solar). O solo da área experimental foi classificado como Latossolo Vermelho Eutrófico, A moderado, textura média, segundo EMBRAPA (1999). Cada área (ambiente protegido e campo) possuía três canteiros de plantio, de $36 \mathrm{~m}$ de comprimento e $1 \mathrm{~m}$ de largura, com espaçamento de $1 \mathrm{~m}$ entre canteiros. Cada canteiro possuía três linhas de cultivo, espaçadas de $0,30 \mathrm{~m}$ entre fileiras e $0,20 \mathrm{~m}$ entre plantas.

A planta cultivada foi o Tagetes patula (cravo-de-defunto), com 15 a $20 \mathrm{~cm}$ de altura, de flores simples e dobradas, em tonalidades de amarelo, laranja, vermelho, marrom-claro ou em combinações dessas cores.

As mudas do Tagetes patula, a serem utilizadas nas duas condições de cultivo (ambiente protegido e campo), foram pre- paradas no viveiro de mudas florestais da FCA-Botucatu. A semeadura foi feita no dia 16/04/2002 utilizando-se bandejas de polietileno expandido (isopor) de 128 células, semeando uma semente por célula, em substrato comercial (Plantmax)®. As bandejas permaneceram dentro de ambiente protegido recebendo irrigação e a aplicação de nitrato de cálcio e cal de pintura, como fertirrigação, 2 vezes ao dia, manualmente. No dia 20/05/02, 34 dias após a semeadura, as mudas mais vigorosas foram transplantadas para os canteiros da área experimental (ambiente protegido e campo), com densidade de 15 plantas/ $\mathrm{m}^{2}$.

O preparo do solo dos canteiros foi feito com enxada rotativa e enxadão sete dias antes do transplante das mudas. De acordo com os resultados da análise química do solo, nenhuma prática de adubação inicial foi recomendada.

Foi utilizado o sistema de irrigação por gotejamento, com tubos gotejadores distribuídos ao longo das linhas de plantio, com espaçamento de $0,30 \mathrm{~m}$ entre eles.

Para garantir o pleno desenvolvimento da cultura, foram feitas capinas manuais para o controle de plantas daninhas. 
$\mathrm{O}$ encerramento das atividades no experimento se deu no dia 09/08/02, 81 dias após o transplante das mudas, quando as plantas mostraram queda no índice de área foliar (IAF) e um aspecto de senilidade.

2.2. Amostragem das plantas e medidas após o transplante

A avaliação do crescimento e desenvolvimento das plantas de Tagetes patula foi feita de acordo com os estádios de desenvolvimento da cultura, proposto por Boueri (2003), levando-se em consideração diversas variáveis, tais como: altura, comprimento das raízes, número de folhas, número de botões florais, área foliar (AF) e índice de área foliar (IAF). Estas foram avaliadas de acordo. Para tanto, observações e medições semanais eram realizadas, à partir do sétimo dia após o transplantio das mudas, fazendo-se necessário a colheita de quatro plantas aleatórias em cada área de cultivo (ambiente protegido e campo).

A altura das plantas foi medida da base do caule até as folhas mais altas, utilizando-se uma régua graduada em centímetros que também foi utilizada para a medida do comprimento das raízes. $\mathrm{O}$ número de folhas e botões florais foi obtido por contagem individual de cada planta.

A área foliar, em centímetros quadrados, foi obtida com o auxílio de um Medidor de Superfície Laminar, modelo MSL -80 .

Para determinar o índice de área foliar (IAF), foram utilizadas as medidas de área foliar total de quatro plantas (AF em $\mathrm{m}^{2}$ ) e respectiva área de solo disponível para a planta $(\mathrm{m} 2)$, calculando como se segue:

\subsection{Metodologia Estatística}

Para todas as variáveis foi realizada a análise de variância, no esquema fatorial, seguida do método de Tukey quando necessário.

\section{RESULTADOS E DISCUSSÃO}

Os valores médios e o desvio padrão da altura das plantas, por estádio fenológico, em ambiente protegido e a campo, são apresentados na tabela 1 , mostrando que em ambiente protegido, o estádio III (Floração) teve média maior que o estádio I, enquanto que no campo, não houve diferença entre as médias dos estádios. Comparando os dois cultivos, somente o estádio III mostrou diferença significativa, sendo a média do ambiente protegido maior que a do campo.

Tabela 1. Média e desvio-padrão referentes à altura da planta, em cm, durante o ciclo da cultura do Tagetes patula, nas condições de ambiente protegido e campo

Table 1. Referring average and shunting line-standard to the height of the plant, in cm, during the cycle of the Tagetes patula crop, inside and outside of greenhouse

\begin{tabular}{|c|c|c|}
\hline \multirow{2}{*}{ Estádio fenológico } & \multicolumn{2}{|c|}{ Cultivo } \\
\hline & Ambiente protegido & Campo \\
\hline I & $14,7 \pm 1,2$ a B & $14,1 \pm 1,7$ a $\mathrm{A}$ \\
\hline II & $17,4 \pm 2,9$ a $\mathrm{AB}$ & $16,2 \pm 2,2$ a $A$ \\
\hline III & $19,0 \pm 3,3$ a $A$ & $16,0 \pm 1,9 \mathrm{~b} \mathrm{~A}$ \\
\hline IV & $17,0 \pm 2,6$ a $A B$ & $17,0 \pm 1,7$ a $\mathrm{A}$ \\
\hline Média do Cultivo & $17,7 \pm 3,2$ & $16,0 \pm 2,0$ \\
\hline
\end{tabular}

Letras minúsculas comparam média de cultivo dentro de cada estádio fenológico.

Letras maiúsculas comparam médias de estádio fenológico dentro de cada cultivo.

Para o comprimento das raízes, os resultados mostram que não houve diferença entre cultivos e nem houve efeito da interação cultivo x estádio fenológico. A média do estádio I foi inferior às demais médias dos outros estádios (Tabela 2).

Os valores do número de botões florais por planta não mostraram diferença entre os ambientes de cultivo e nem efeito da interação cultivo x estádio fenológico. Houve um crescente no decorrer do tempo (Tabela 3).

Quanto ao número de folhas por planta, a tabela 4 mostra que não houve efeito da interação cultivo $\mathrm{x}$ estádio fenológico e comparando os cultivos, a média do ambiente protegido foi superior à média do campo.

Os valores médios e desvio padrão da área foliar (AF) da planta, por estádio fenológico, em ambiente protegido e cam- po, são apresentados na tabela 5. Observa-se que não houve efeito da interação cultivo x estádio fenológico e a média do ambiente protegido foi superior à média do campo.

Através das figuras 4 (a), (b) e (c), observa-se que os valores do IAF em ambiente protegido são maiores que na condição de campo, indicando que em ambiente protegido as plantas tiveram um maior número de folhas e folhas de maior tamanho.

Quanto à produção de flores, a figura 4 (d) mostra que houve um crescente do número de botões florais por planta no decorrer do ciclo. À partir da $9^{a}$ semana, apesar de ainda se ter produção, as flores já começam a entrar em senescência. As plantas do ambiente protegido apresentaram flores de melhor qualidade, evidenciado a influência positiva do ambiente protegido neste parâmetro. 
Tabela 2. Média e desvio-padrão referentes ao comprimento das raízes, em cm, durante o ciclo da cultura do Tagetes patula, nas condições de ambiente protegido e campo

Table 2. Referring average and shunting line-standard to the length roots, in cm, during the cycle of the Tagetes patula crop, inside and outside of greenhouse

\begin{tabular}{ccc}
\hline \multirow{2}{*}{ Estádio fenológico } & \multicolumn{2}{c}{ Cultivo } \\
\cline { 2 - 3 } & Ambiente protegido & Campo \\
\hline I & $14,1 \pm 2,6$ & $13,6 \pm 3,7$ \\
II & $16,7 \pm 5,1$ & $16,9 \pm 4,6$ \\
III & $18,1 \pm 3,9$ & $19,3 \pm 4,9$ \\
IV & $17,9 \pm 2,3$ & $18,6 \pm 3,9$ \\
\hline Média do Cultivo & $17,1 \pm 4,3$ & $17,7 \pm 4,9$ \\
\hline
\end{tabular}

Tabela 3. Média e desvio-padrão referentes ao número de botões florais por planta, durante o ciclo da cultura do Tagetes patula, nas condições de ambiente protegido e campo

Table 3. Referring average and shunting line-standard to the number floral buttons for plant, during the cycle of the Tagetes patula crop, inside and outside of greenhouse

\begin{tabular}{ccc}
\hline \multirow{2}{*}{ Estádio fenológico } & \multicolumn{2}{c}{ Cultivo } \\
\cline { 2 - 3 } & Ambiente protegido & Campo \\
\hline I & $2,8 \pm 0,7$ & $1,9 \pm 0,8$ \\
II & $20,8 \pm 10,4$ & $14,8 \pm 10,1$ \\
III & $48,3 \pm 19,2$ & $38,8 \pm 13,3$ \\
IV & $61,7 \pm 24,6$ & $61,6 \pm 22,5$ \\
\hline Média do Cultivo & $34,1 \pm 23,9$ & $27,8 \pm 21,3$ \\
\hline
\end{tabular}

Tabela 4. Média e desvio-padrão referentes ao número de folhas por planta, durante o ciclo da cultura do Tagetes patula, nas condições de ambiente protegido e campo

Table 4. Referring average and shunting line-standard to the leaf number for plant, during the cycle of the Tagetes patula crop, inside and outside of greenhouse

\begin{tabular}{ccc}
\hline \multirow{2}{*}{ Estádio fenológico } & \multicolumn{2}{c}{ Cultivo } \\
\cline { 2 - 3 } & Ambiente protegido & Campo \\
\hline I & $18,0 \pm 6,6$ & $11,5 \pm 3,8$ \\
II & $109,8 \pm 50,1$ & $77,0 \pm 57,5$ \\
III & $218,8 \pm 89,2$ & $172,7 \pm 53,9$ \\
IV & $228,1 \pm 112,1$ & $203,3 \pm 89,0$ \\
\hline Média do Cultivo & $156,0 \pm 100,7 \mathrm{a}$ & $121,4 \pm 83,1 \mathrm{~b}$ \\
\hline
\end{tabular}

Letras minúsculas comparam médias dos cultivos.

Tabela 5. Média e desvio-padrão referentes à área foliar (AF) da planta, em $\mathrm{cm} 2$, durante o ciclo da cultura do Tagetes patula, nas condições de ambiente protegido e campo

Table 5. Referring average and shunting line-standard to the foliar area (AF) of the plant, in cm2, during the cycle of the Tagetes patula crop, inside and outside of greenhouse

\begin{tabular}{ccc}
\hline Estádio fenológico & & Cultivo \\
\cline { 2 - 3 } & Ambiente protegido & Campo \\
\hline I & $374,8 \pm 142,3$ & $791,7 \pm 97,0$ \\
II & $1834,1 \pm 780,9$ & $722,9 \pm 513,9$ \\
III & $2440,4 \pm 811,5$ & $1318,7 \pm 452,9$ \\
IV & $2036,5 \pm 370,8$ & $1477,1 \pm 1217,1$ \\
\hline Média do Cultivo & $1807,6 \pm 990,5 \mathrm{a}$ & $911,5 \pm 658,9 \mathrm{~b}$ \\
\hline
\end{tabular}

Letras minúsculas comparam médias dos cultivos. 
(a)

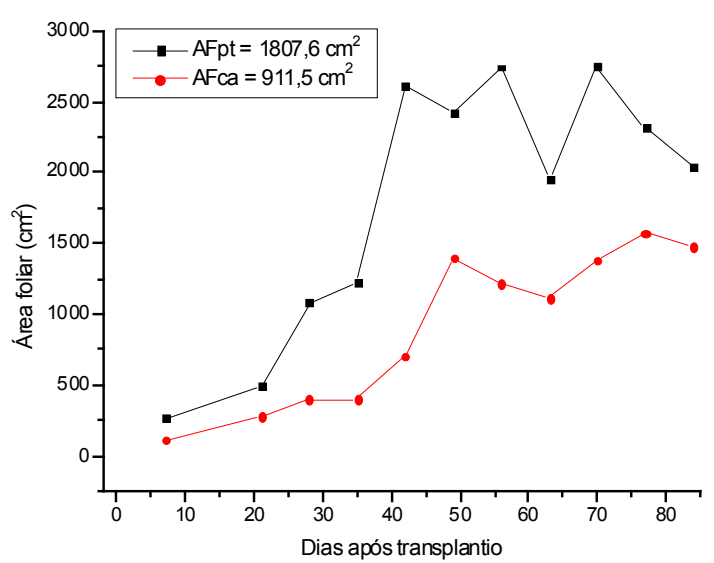

(c)

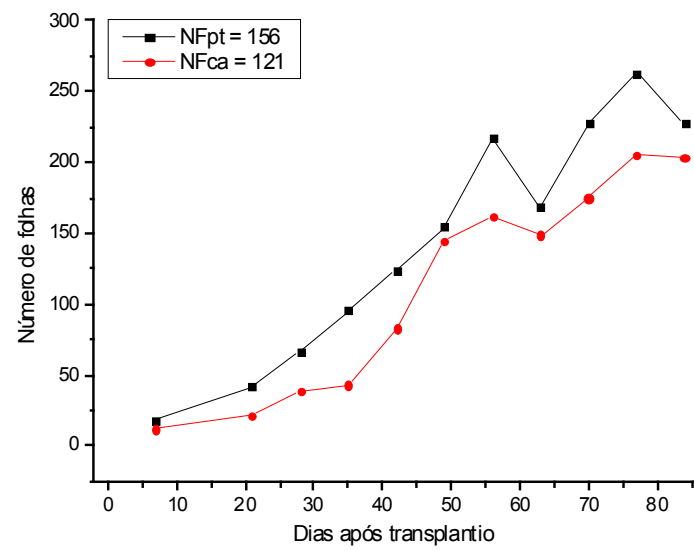

(b)

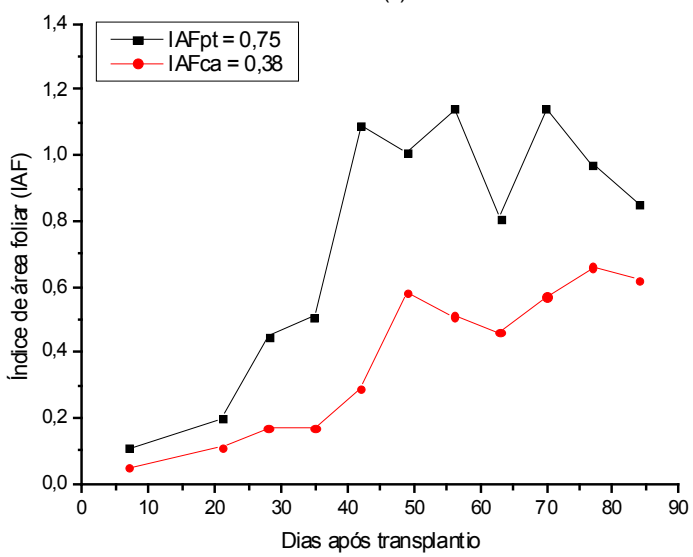

(d)

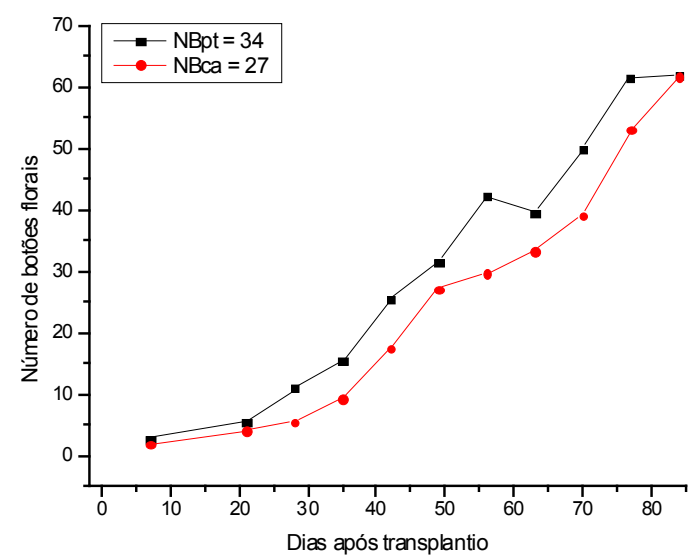

Figura 4. Valores médios de área foliar (AF) (a), índice de área foliar (IAF) (b), número de folhas (c) e número de botões florais (d) por planta, durante o ciclo da cultura do Tagetes patula, nas condições de ambiente protegido (pt) e campo (ca).

Figure 4. Average values of foliar area $(A F)(a)$, index foliar area $(I A F)(b)$, leaf number (c) and number floral buttons (d) for plant, during the cycle of the Tagetes patula crop, inside (pt) and outside (ca) of greenhouse.

\section{CONCLUSÕES}

A partir dos resultados obtidos, conclui-se que:

1. Os valores da altura média das plantas, número médio de folhas por planta, área foliar e índice de área foliar médio em ambiente protegido foram maiores que na condição de campo. 2. O comprimento das raízes e o número de botões florais não apresentaram diferenças significativas entre as duas condições. 3. As plantas do ambiente protegido apresentaram flores de melhor qualidade, evidenciado a influência positiva do ambiente protegido neste parâmetro.

\section{AGRADECIMENTOS}

À CAPES, pela concessão da bolsa de estudos e à Melania Inês Valiatti pela colaboração na montagem e condução do experimento.

\section{REFERÊNCIAS}

BELCHER, J.V.; HUSSEY, R.S. Influence of Tagetes patula and Arachis hypogaea on Meloidogyne incognita. Plant Disease Reporter, v.61, n.7, p.525-28, 1977.

BOUERI, M. A. Caracterização do saldo de radiação em ambiente protegido e a campo e seus efeitos sobre as ne- cessidades hídricas do cravo-de-defunto (Tagetes sp.). 2003. 62f. Dissertação (Mestrado em Agronomia/Energia na Agricultura)-Faculdade de Ciências Agronômicas, Universidade Estadual Paulista, Botucatu, 2003.

CLARCK, D.E.; WILLIAMSON, J.F. New western garden book. Menlo Park Lane Publishing Co., 1979. 480p.

ENCICLOPÉDIA de plantas e flores. Abril cultural, 1977. $174 \mathrm{p}$.

EMBRAPA - Empresa Brasileira de Pesquisa Agropecuária. Centro Nacional de Pesquisa de Solos. Sistema Brasileiro de Classificação de Solos, Rio de Janeiro, 1999. 412p.

FLORTEC. Produção de forrações para paisagismo e jardinagem. Edições FLORTEC, 1998. 23 p.

HACKNEY, R.W.; DICKERSON, O.J. Marigold, castor bean, and chrysanthemum as controls of Meloidogyne incognita and Pratylenchus alleni. Journal of Nematology, v.7, n.1, p.8490, 1975.

HUANG, S.P. Cropping effects of marigolds, corn, and okra on population levels of Meloidogyne javanica and on Carrot Yields. Journal of Nematology, v.16, n.4, p.396-398, 1984. 
KÄMPF, A.N. Produção comercial de plantas ornamentais. Guaíba-RS: Editora Agropecuária, 2000. 219p.

LORENZI, H.; SOUZA, H.M. Plantas ornamentais no Brasil. Arbustivas, herbáceas e trepadeiras. São Paulo: Editora Plantarum, 1995. 720 p.

MEDINA, A. L.; BEMILLER, J.N. Marigold flower meal as a source of na emulsifiying gum. In: J.Janick and J.E.Simon. New crops. New York: Wiley, 1993.

ODUOR-OWINO, P.; WAUDO, S.W. Comparative efficacy of nematicides and nematicidal plants on root-knot nematodes.
Trop. Agric. (Trinidad), v.71, n.4, p.272-74, 1994.

TYGADLO, J.A.; MAESTRI, D.M.; ARIZA, E.L. The volatile oil of Tagetes argentina Cabrera. Journal of Essential Oil Research, v.5, p.185-186, 1993.

VASILENKO, Y.U.K.; BOGDANOV, A.N.; FROLOV, L.M.; FROLOV, A.V. Hepatoprotective properties of preparation from spreading marigold. Khim-Farm Zh, v.24, p.153-56, 1990.

VASUDEVAN, P.; KASHYAP, S.; SHARMA, S. Tagetes: A multipurpose plant. Bioresource Tecnology, v.62, n.1-2, p.2935, 1997. 